1

2

3

4

5

6

7

8

9

10

11

12

13

14

15

16

\#corresponding author: sxh106@gmail.com

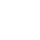

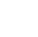

\title{
Social signaling via bioluminescent blinks drives schooling behavior in the flashlight fish Anomalops katoptron
}

Peter Jägers ${ }^{1}$, Louisa Wagner ${ }^{1}$, Robin Schütz ${ }^{1}$, Maximilian Mucke ${ }^{1}$, Budiono Senen ${ }^{2}$

Gino V. Limmon ${ }^{3,4}$, Stefan Herlitze $^{1 \#}$, Jens Hellinger ${ }^{1}$ ${ }^{1}$ Department of General Zoology and Neurobiology, Institute of Biology and Biotechnology, Ruhr-University Bochum, 44780
Bochum, Germany

17 


\section{Abstract}

20 The bioluminescent flashlight fish Anomalops katoptron live in schools of several hundred specimens.

21 To understand how flashlight fish, integrate bioluminescent signaling into their schooling behavior,

22 we analyzed movement profiles and blink frequencies. Isolated specimen of $A$. katoptron show a high motivation to align with fixed or moving artificial light organs. Depending on presented frequencies A. katoptron responds with a reduction in swimming speed and its own blink frequency. Higher presented blink frequencies reduce the nearest neighbor distance. In the natural environment A. katoptron is changing its blink frequencies and nearest neighbor distance in a context specific manner. Blink frequencies are increased from day to night and during avoidance behavior, while nearest neighbor distance is decreased with increasing blink frequencies. A. katoptron changes its blink frequencies by modifying light organ occlusion. Our results suggest that visually transmitted information via specific blink patterns determine intraspecific communication and group cohesion in schooling A. katoptron. 
Bioluminescence is a widespread phenomenon in ocean-dwelling organisms including a broad phylogenetic distribution in marine fish ${ }^{1}$. In ray finned fish bioluminescence evolved independently at least 27 times ${ }^{2}$. In vertebrates only fish possess the ability to emit light via own photophores, bioluminescent bacteria hosted within specialized light organs or kleptoproteins acquired from prey 3 .

Numerous functions of bioluminescence have been described and suggested such as counterillumination ${ }^{4,5}$, mate attraction ${ }^{6}$, prey attraction ${ }^{7}$ and prey illumination in flashlight fish (Anomalopidae) ${ }^{8}$. All members of the family Anomalopidae such as Photoblepharon and Anomalops are characterized by bean-shaped, subocular light organs 9,10. In Photoblepharon steinitzi three distinct functions in bioluminescent signaling like finding prey, intraspecific communication and confusing predators via a "blink and run-pattern" have been proposed ${ }^{11,12}$. Photoblepharon reside solitary- or pairwise in territories (e.g. reef caves) while Anomalops katoptron (Anomalopidae) occur in large, moving schools during moonless nights ${ }^{8,13}$.

The extrinsic, continuous bioluminescent light in A. katoptron is produced by symbiotic bioluminescent bacteria Candidatus photodesmus katoptron (Gammaproteobacteria: Vibrionaceae) hosted within subocular light organs. Anomalopid symbionts show a genome reduction like other unrelated, obligate symbiotic bacteria, such as insect endosymbionts. It has been proposed that symbionts of $A$. katoptron are transmitted during an active environmental phase ${ }^{14-16}$. Symbiotic bacteria are densely packed in numerous tubules that are aligned at right angles to the light-emitting surface of light organs ${ }^{8,16,17}$. The inner surface of light organs contains two stacks of guanine crystals, which serve as reflector to enhance light emission ${ }^{18}$. At the anterior edge light organs are attached to suborbital cavities via the rod like "Ligament of Diogenes" which allows a downward rotation. This exposes the dark pigmented back of light organs and disrupts light output. The visual system of A. katoptron is optimized to detect wavelengths in the frequency range of its own bioluminescent symbionts ${ }^{19,20}$. Fascinating blink patterns of large schools can be observed on coral reefs in the IndoPacific during dark and moonless nights ${ }^{13,21}$. During the daytime $A$. katoptron hides in crevices, caves or deep water ${ }^{8,21}$.

In general, groups of fish show various formations ranging from lose aggregations to highly aligned groups moving in synchronized directions ${ }^{22,23}$. Living in a group can be advantageous in several aspects like lower predation risk, mate choice ${ }^{24}$, reduced metabolic costs ${ }^{25}$ and higher probability in detecting food sources ${ }^{26}$. It has been proposed that a synchronized organization within the school 
leads to lower vulnerability ${ }^{27}$. Group size and cohesion play an important role in schooling and can reduce the risks of being preyed through attack abatement ${ }^{28}$ or confusion of predators ${ }^{29}$.

The ability to sense intraspecific group members is important to maintain the formation of a school ${ }^{30}$. Sensory input from vision and lateral lines are integrated to determine attraction or repulsion in moving groups. Partridge \& Pitcher suggested that vision is primarily used for maintenance of position and angle between fish while lateral lines monitor swimming speed and direction of moving neighbors ${ }^{31}$. The school formation is situation-dependent and can be interpreted as an integration of surrounding ecological factors. For example higher predation regimes force shoaling groups of Poecilia reticulata (Poecillidae) to form denser aggregations with closer nearest neighbor distance 27,32. Collective behavior has been recently analyzed with computer models and/or robotic dummies revealing strong correlation between decision rules of individuals driving group behavior ${ }^{33-36}$.

Providing information to conspecifics is an important feature to maintain the functionality of a dynamic group and can be observed on inter-individual and/or group level ${ }^{35}$. Many different ways of intraspecific communication are described within fish just as mutual allocation in the weakly electric fish Mormyrus rume proboscirostris (Mormyridae) via electrocommunication that leads to social attention ${ }^{37}$ or startle response as a reaction on moving neighbors in Clupea harengus (Clupeidae) ${ }^{38}$.

As nocturnal animals live under visual restriction, bioluminescent signaling can become an additional source of information ${ }^{7}$ e.g. in orientation towards conspecifics shown in ostracodes (Cypridinidae) 39,40 , dragonfish (Stomiidae) ${ }^{41,42}$ or pony fish (Leiognathidae) ${ }^{43}$. For Gazza minuta (Leiognathidae) discrete projected luminescent flashes have been described. Possible functions are spacing between foraging individuals, keeping the school together or reproductive activities each represented in different flash patterns ${ }^{44}$.

It has been shown that $A$. katoptron uses its light organs to actively localize food. During feeding the light organs reveal a prolonged exposure and shorter occlusion time resulting in decreased blink frequencies ${ }^{8}$. In addition, it has been described that the light organs play a role in orientation towards conspecifics in schooling behavior of $A$. katoptron ${ }^{13}$.

In this study we investigated how A. katoptron behaviorally responds to different artificial light stimuli and if these behavioral responses can be compared to a context-dependent blinking behavior observed in the natural environment at the Banda Sea. We found that A. katoptron is attracted by blue green light $(500 \mathrm{~nm})$ in a blink frequency and light intensity dependent manner. The fish responds with an adjustment of its own blink frequencies, where the light organ occlusion, but not the exposure time is adjusted. Higher blink frequencies are correlated with closer nearest neighbor distance leading to a higher group cohesion. Thus, our study shows for the first time that the blink 
bioRxiv preprint doi: https://doi.org/10.1101/2020.06.16.143073; this version posted June 16, 2020. The copyright holder for this preprint (which was not certified by peer review) is the author/funder, who has granted bioRxiv a license to display the preprint in perpetuity. It is made available under aCC-BY-NC-ND 4.0 International license.

97 frequencies of the bioluminescent light of the flashlight fish A. katoptron is used for a context 98 dependent, intraspecific communication. 


\section{$\underline{\text { Results }}$}

To investigate how bioluminescent signaling emitted by the light organs of the splitfin flashlight fish Anomalops katoptron is used for intraspecific communication, we investigated the behavioral responses of isolated flashlight fish to artificial light pulses in the laboratory. It has been suggested that $A$. katoptron in its natural environment reveal a schooling behavior. To investigate if and how A. katoptron reacts to different light signals we isolated A. katoptron in an experimental tank (Fig. 1A, 1B). In the middle of the tank we introduced a light emitting dummy and defined two areas, where we analyzed the duration of how long the fish spend in this area, i.e. one area close to the dummy (center area) and one area close to the exit area (exit door) of the tank. This exit door is normally open and connects the experimental tank with the housing tank. Without light stimulation individuals stayed for $64.4 \pm 5.7 \%$ (Fig. 1A, 1C) of the time in the exit area compared to the center area. Fish were swimming with a swimming speed of $0.19 \pm 0.01 \mathrm{~m} / \mathrm{s}$ (Fig. 1D). Stimulation with artificial light organs caused an orientation towards the fish dummy (Fig. 1B). Isolated specimen spent $79.7 \pm 3.9 \%$ of the time in the center around the light emitting dummy (LED timing: $2 \mathrm{~Hz}$, $0.25 \mathrm{~s}$ on $+0.25 \mathrm{~s}$ off) and reduced their swimming speed. (Fig. 1C and 1D, Video S1).

Control experiments showed that the shape of the dummy does not have an impact on the behavior of A. katoptron (Fig. S1). These findings suggest that light pulses are used for intraspecific communication of $A$. katoptron and that $A$. katoptron is attracted by these light pulses (Fig. 1).

To investigate if the light intensity of light pulses plays a role for intraspecific communication, we determined the emitted light intensity of A. katoptron's light organs. Light emitted by luminous bacteria housed within the light organs of $A$. katoptron had a maximum intensity of $0.27 \mu \mathrm{W}$ (emission peak at $510 \mathrm{~nm}$ wavelength, $\mathrm{n}=5$; Fig. S2). We next applied LED light stimuli $(1 \mathrm{~Hz}$, $0.5 \mathrm{~s}$ on $+0.5 \mathrm{~s}$ off) with light intensities of $0.12,0.33$ and $1.52 \mu \mathrm{W}$ (at $504 \mathrm{~nm}$ wavelength) and found that increasing light intensities resulted in decreased blink frequencies. There were no differences in distances kept to the dummy (around $15.67 \pm 0,64 \mathrm{~cm}$ ). Thus, throughout the experiments we used a LED light, with an intensity at $504 \mathrm{~nm}$ wavelength of $0.23 \mu \mathrm{W}$ (except for the intensity experiments), which is slightly dimmer than the light emitted from the light organ of $A$. katoptron.

To investigate if the blink frequency is important for intraspecific communication, we presented three different blink frequencies $(0.5 \mathrm{~Hz} ; 1 \mathrm{~Hz} \& 2 \mathrm{~Hz})$ with equally distributed LED light on- and offtimes (Fig. 1C-F). While there was no difference in time spent in the center area (Fig. 1C), there was a frequency-dependent change in swimming speed (Fig. 1D), the blink frequency response (Fig. 1E) along with the exposure and occlusion of the light organs (Fig. 1F). A light stimulation of $0.5 \mathrm{~Hz}$ resulted in a swimming speed of $0.146 \pm 0.009 \mathrm{~m} / \mathrm{s}$, which is faster than the swimming speed 
bioRxiv preprint doi: https://doi.org/10.1101/2020.06.16.143073; this version posted June 16, 2020. The copyright holder for this preprint (which was not certified by peer review) is the author/funder, who has granted bioRxiv a license to display the preprint in perpetuity. It is made available under aCC-BY-NC-ND 4.0 International license.
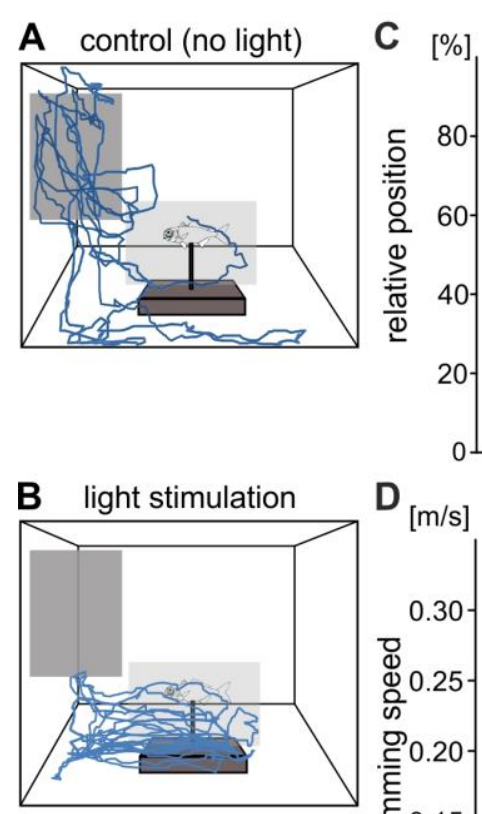

$\mathbf{D}_{[\mathrm{m} / \mathrm{s}]}$

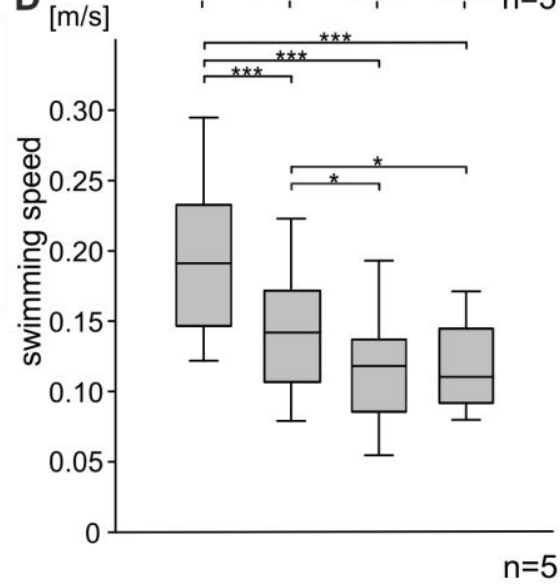

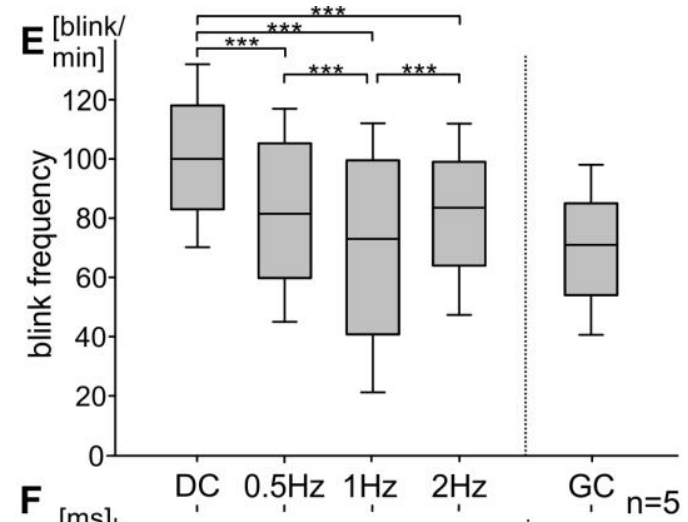

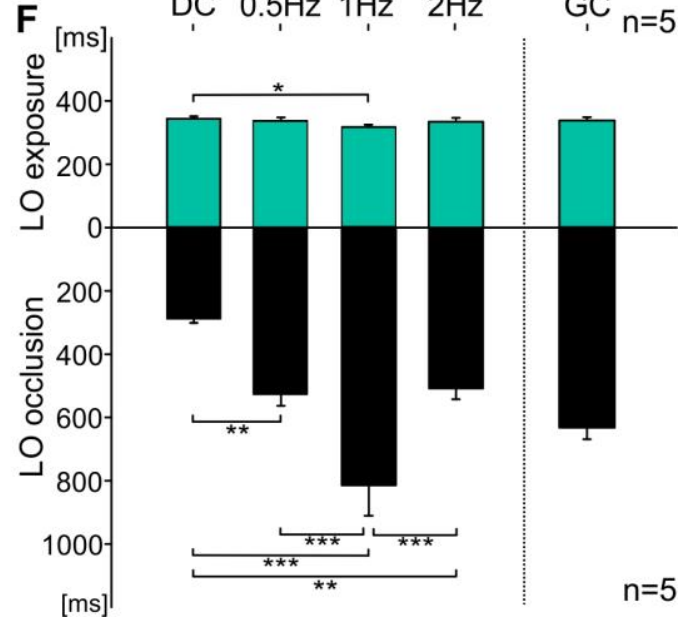

Figure 1. Changes in positioning, swimming speed, blink frequency and light organ occlusion of flashlight fish (A. katoptron) induced by a fish dummy equipped with artificial light organs.

(A, B) Example of two- dimensional trajectories for (A) control without and (B) $1 \mathrm{~Hz}$ stimulation (LED light pulses with equal distributed on- and off times) of isolated flashlight fish ( $n=5)$. Boxes indicate the two defined areas of interest, which were analyzed. Dark gray is defined as "Exit Area" and light gray as "Center", where the dummy with artificial light organs was placed. Each trajectory was traced for $60 \mathrm{~s}$.

(C) Relative Positioning ( \pm SEM) of isolated A. katoptron $(n=5)$ in areas of interest during four different stimuli (DC, dark control; 0.5, 1, $2 \mathrm{~Hz}$ blinking LED with equal distributed LED on- and off- times within artificial light organs).

(D) Swimming speed (m/s) of isolated A. katoptron $(\mathrm{n}=5)$ during four different stimuli (DC; 0.5, 1, $2 \mathrm{~Hz}$ blinking LED with equal distributed LED on- and off- times).

(E) Blink frequencies of $A$. katoptron $(n=5)$ induced by four stimuli (DC; $0.5,1,2 \mathrm{~Hz}$ blinking LED with equal distributed LED on- and off- times). Additionally, blink frequencies of a group consisting of five individuals (GC), which is divided by a scattered line, were analyzed. Individuals were tested separately before group experiments.

(F) Mean light organ exposure and occlusion time ( \pm SEM) during four different stimuli and a group control (DC, dark control; 0.5, 1, $2 \mathrm{~Hz}$ blinking LED within artificial light organs with equal distributed LED on- and off- times; GC, group control). Upper lines refer to stimulation as seen in (E). Greenish bars indicate exposure of light organs and occlusion of light organs is represented by black bars $(n=5)$.

DC, dark control; GC, group control. Significance values are reported as $* p<0.05, * * p<0.01, * * * p<0.001$. Error bars indicate \pm SEM. 
We next analyzed the blink frequency responses of $A$. katoptron. We found that during schooling behavior in the tank the average blink frequency of individuals was $1.17 \mathrm{~Hz}(69.88 \pm 1.78$ blinks $/ \mathrm{min})$, while in isolation the blink frequency is increased to $1.67 \mathrm{~Hz}(100.39 \pm 1.83 \mathrm{blinks} / \mathrm{min})$. At $1 \mathrm{~Hz}$ LED light stimulation, the blink frequency of A. katoptron was $70.25 \pm 2.72$ blinks/min and was comparable to the blink frequency within the school (i.e. $1.17 \mathrm{~Hz}$ ), but is increased to $1.35 \mathrm{~Hz}$ for $0.5 \mathrm{~Hz}$ and $2 \mathrm{~Hz}$ light stimulation.

Next we investigated mean light organ exposure and occlusion for the different experimental light pulse settings. We found that the time individuals expose light organs is around $330 \mathrm{~ms}$, which was comparable throughout the experiments (DC $(344 \pm 0.005 \mathrm{~ms}), 0.5 \mathrm{~Hz} \quad(338 \pm 0.004 \mathrm{~ms}), 1 \mathrm{~Hz}$ (317 $\pm 0.006 \mathrm{~ms}), 2 \mathrm{~Hz}(336 \pm 0.008 \mathrm{~ms}) ;$ Fig. 1F). In contrast, differences existed in how long the organ is occluded. We found that in isolation the fish decreases its occlusion time to $287 \pm 0.01 \mathrm{~ms}$, while during schooling $(618 \pm 0.069 \mathrm{~ms})$ and in the presence of the light stimuli, light organ occlusion increased $(0.5 \mathrm{~Hz}(528 \pm 0.035 \mathrm{~ms}), 1 \mathrm{~Hz}(967 \pm 0.092 \mathrm{~ms}), 2 \mathrm{~Hz}(0.507 \pm 0.036 \mathrm{~ms}) ;$ Fig. 1F). These findings suggest that light organ occlusion defines blink frequencies during schooling.

Thus, the findings on blink frequencies related to light organ occlusion, orientation and swimming speed led us to the hypothesis that the timing of light pulses emitted by A. katoptron bear information to keep attraction and alignment of $A$. katoptron to its conspecifics.

To investigate this hypothesis, we established a second experimental setup in a circular arena tank, with a light pulse emitting dummy in the middle of the arena (Fig. 2A). We changed the LED off-times between $200 \mathrm{~ms}$ and $500 \mathrm{~ms}$ with on-times at $300 \mathrm{~ms}$ and examined the distance of the individuals towards the artificial light organs of the dummy in the center using heat maps. Without light stimulation individuals were swimming along the wall and avoiding the middle of the arena (Fig. 2C1) with a mean distance of $42.25 \pm 0.76 \mathrm{~cm}$ to the dummy (Fig. 2B). During light stimulation A. katoptron changed its swimming behavior in an off-time dependent manner (Fig. 2C2-3). A $500 \mathrm{~ms}$ LED off-time resulted in a closer but still partly decentralized orientation $(23.63 \pm 0.88 \mathrm{~cm})$ towards the dummy in comparison to the dark control (DC; RM ANOVA: $p<0.001$, Fig. 2C2; Video S2). The closest and centralized orientation towards the LED dummy occurred with 200 ms off-time LED stimulation (Fig. 2C3). These findings suggest that light organ occlusion contains information about nearest neighbor distance for $A$. katoptron. 
A

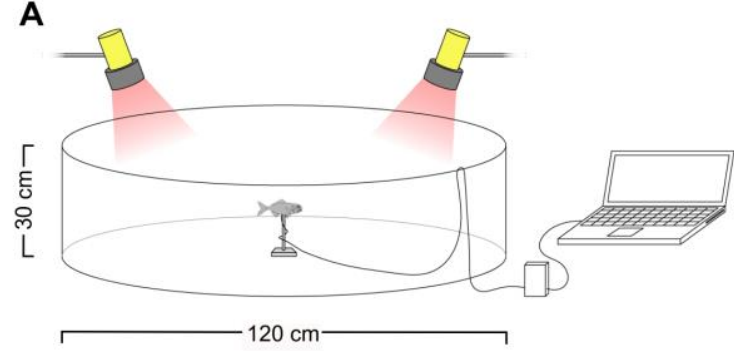

B

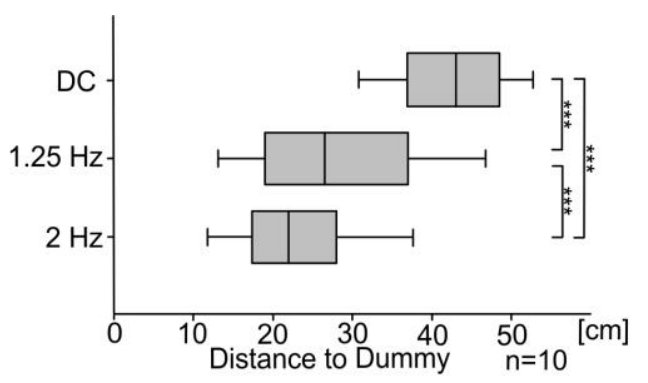

C1

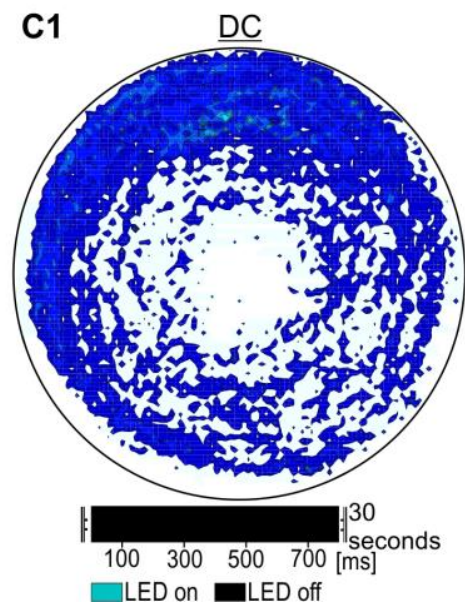

C2
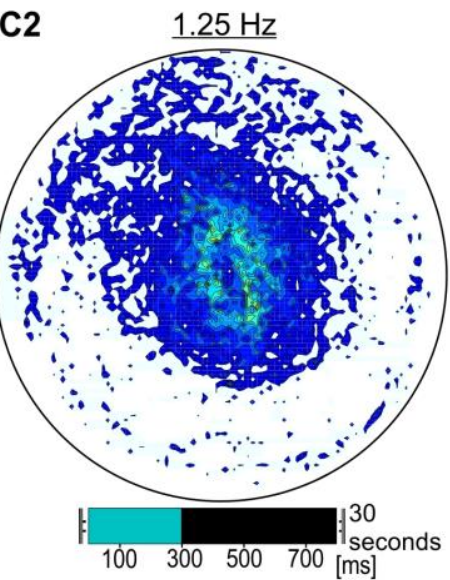

C3 $\quad \underline{\mathrm{Hz}}$

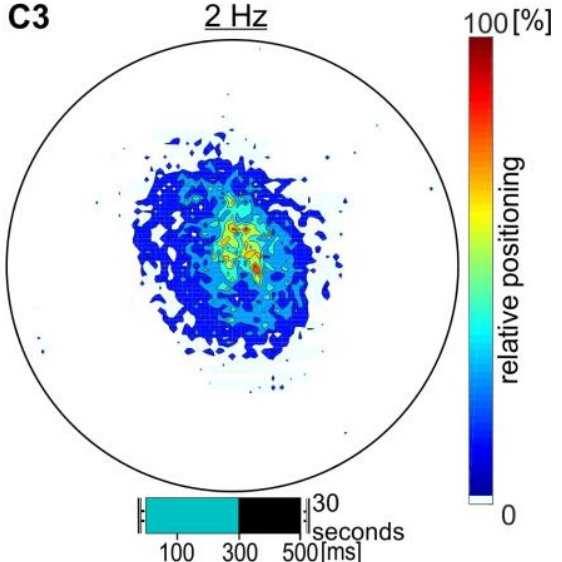

Figure 2. Nearest neighbor distance communicated via artificial light organs within flashlight fish (A. katoptron).

(A) Experimental setup for the validation of changes in nearest neighbor distance. Artificial light organs of a center placed dummy were emitting different light stimulations $(1.25 \mathrm{~Hz}$, LED off-time $500 \mathrm{~ms} ; 2 \mathrm{~Hz}$ LED offtime $200 \mathrm{~ms}$ ) for 30 seconds. An additional control without light stimulation was performed (DC, dark control). In this experiment LED off-timing was adjusted while LED on-time was consistent for 300 ms.

(B) Distance between isolated specimen $(n=10)$ and the center placed fish dummy equipped with artificial light organs.

(C) Heat Maps indicate relative positioning of A. katoptron ( $\mathrm{n}=10)$ in relation to a light (C2/C3) or no light (C1) emitting dummy. A closer orientation can be observed with shorter intervals $(200 \mathrm{~ms})$ between constant light emittance of $300 \mathrm{~ms}$. Without light stimulation individ

DC, dark control. Significance values are reported as: ${ }^{*} p<0.05,{ }^{* *} p<0.01,{ }^{* * *} p<0.001$

In the ocean, schools of $A$. katoptron constantly move through the open water, suggesting that individuals recognize/monitor their nearest neighbor to stay aligned. Thus, we next examined if A. katoptron would follow a moving light signal. To perform this experiment, we used an experimental setup, in which 13 LEDs arranged in a circular swimming tank separated by an angle of $27.7^{\circ}$ lit up for 300 ms consecutively clockwise or counterclockwise (Fig. 3A, S3 and Video S3). without showing off-time-dependency (Fig. S3). A higher swimming speed of A. katoptron was observed for the $200 \mathrm{~ms}$ off-times $(0.285 \pm 0.013 \mathrm{~m} / \mathrm{s})$, representing faster moving LEDs, in comparison to the $500 \mathrm{~ms}$ off-times $(0.246 \pm 0.007 \mathrm{~m} / \mathrm{s})$ and the control without light stimulation 
bioRxiv preprint doi: https:/doi.org/10.1101/2020.06.16.143073: this version posted June 16, 2020. The copyright holder for this preprint (which was not certified by peer review) is the author/funder, who has granted bioRxiv a license to display the preprint in perpetuity. It is made available under aCC-BY-NC-ND 4.0 International license.

(DC; $0.213 \pm 0.008 \mathrm{~m} / \mathrm{s}$ ) (Fig. 3B). In contrast, the fish follows the rotating LEDs at $500 \mathrm{~ms}$ off-times closer and with higher precision $(1.25 \mathrm{~Hz} ; 0.771 \pm 0.013$; Fig. 3C, 3D2) in comparison to $200 \mathrm{~ms}$ offtimes ( $2 \mathrm{~Hz}$; $0.63 \pm 0.023$; Fig. $3 \mathrm{C}, 3 \mathrm{D} 3$ ) and control (DC; $0.365 \pm 0.013$; Fig. 3C, 3D1). The results suggest that $A$. katoptron lose precision to follow artificial light organs at higher swimming speeds.

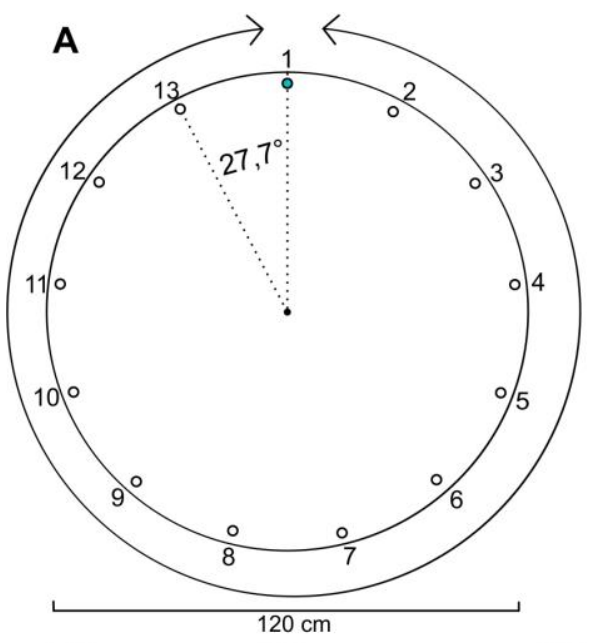

B

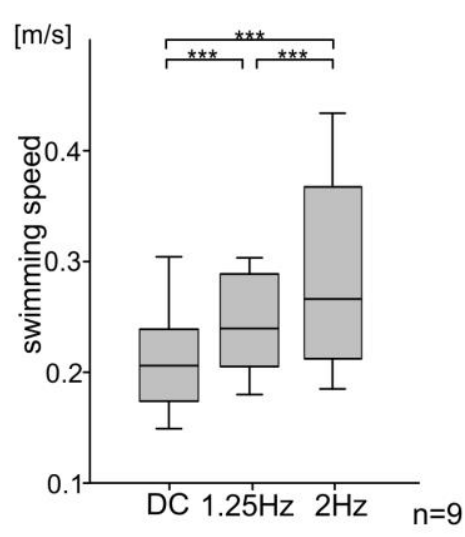

C

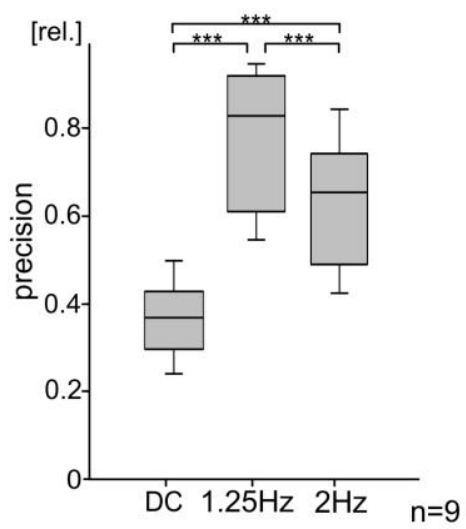

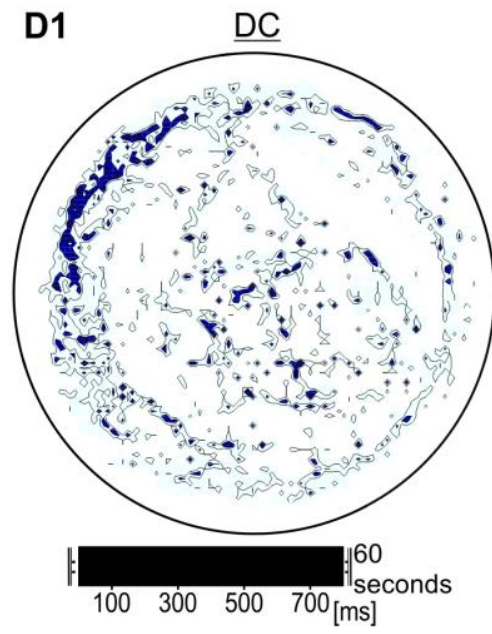
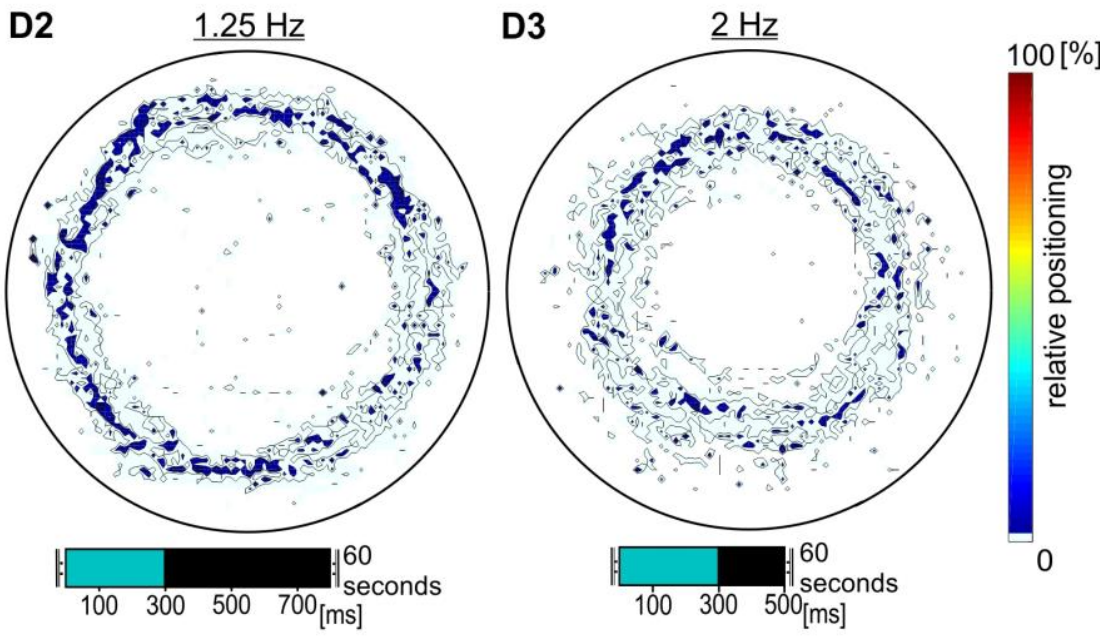
$\square$ LED on $\square$ LED off

Figure 3. Motivation of flashlight fish (A. katoptron) to follow a moving light source.

(A) Experimental setup with 13 wall mounted LEDs that were triggered consecutively counter- or clockwise. Intervals between $300 \mathrm{~ms}$ light emittance were $200 \mathrm{~ms}(2 \mathrm{~Hz})$ or $500 \mathrm{~ms}(1.25 \mathrm{~Hz})$ (travelling speed of light: $200 \mathrm{~ms}, 0.58 \mathrm{~m} / \mathrm{s} ; 500 \mathrm{~ms}, 0.36 \mathrm{~m} / \mathrm{s})$. Each fish was tested for 60 seconds in 5 trials.

(B) Mean swimming speed of isolated A. katoptron $(n=9)$ during control (DC, dark control), $200 \mathrm{~ms}$ off $(2 \mathrm{~Hz})$ and $500 \mathrm{~ms}$ off $(1.25 \mathrm{~Hz})$ times.

220 (C) We estimated relative distance between specimen of A. katoptron $(n=9)$ and the center of the tank according to the motivation of individuals to follow the moving light source.

222 (D) Heat Maps indicate relative positioning of $A$. katoptron $(n=9)$ during light stimulation (D2/D3) and control

223 (D1, DC). Heat Maps are based on five trials for one isolated specimen.

DC, dark control; ${ }^{*} \mathrm{p}<0.05,{ }^{* *} \mathrm{p}<0.01,{ }^{* * *} \mathrm{p}<0.001$ 
225 We next investigated the blinking behavior of several schools of $A$. katoptron in the ocean at a cave 226 near Ambon and on a reef flat of Banda Island, Maluku, Indonesia. During the day the school of

227 A. katoptron could be observed within the cave, while at sunset the school left the cave to approach 228 the reef flat. We also observed a context dependent blink behavior and distinguished three different 229 behavioral conditions, i.e. blinking behavior in the cave during the day, blinking behavior at the reef 230 flat during the night and blinking behavior during avoidance triggered by a red diving torch. As also 231 observed in the aquarium, blink frequencies increased from $1.96 \mathrm{~Hz}$ (cave, $117.69 \pm 1.55 \mathrm{blink} / \mathrm{min}$, 232 Video S4), $3.33 \mathrm{~Hz}$ (reef flat, $199.71 \pm 3.21 \mathrm{blink} / \mathrm{min}$, Video S5) to $3.97 \mathrm{~Hz}$ (avoidance, $233238.45 \pm 4.79 \mathrm{blink} / \mathrm{min}$, Video S6, Fig. 4A) with light organ occlusion ranging from $347.14 \pm 10.8 \mathrm{~ms}$ 234 (cave), $120.66 \pm 2.39 \mathrm{~ms}$ (reef flat) to $68.65 \pm 2.34 \mathrm{~ms}$ (avoidance, RM ANOVA: $p<0,001$ ), while light 235 organ exposure remained constant at around $230 \mathrm{~ms}$ (cave $=229.91 \pm 3.05 \mathrm{~ms}$, reef 236 flat $=219.63 \pm 4.79 \mathrm{~ms}$, avoidance $=233.89 \pm 6.53 \mathrm{~ms}$, Fig. $4 \mathrm{~B}$ ). In addition, we found that the 237 variation in blink frequencies is highest during avoidance behavior (Gaussian distribution; $X$ $\left.238\left(\mu=3.97 \mathrm{~Hz} ; \sigma^{2}=3.062 \mathrm{~Hz}\right)\right)$ and low during daytime, while hiding in the caves (Gaussian distribution; $\mathrm{X}$ $239\left(\mu=1.96 \mathrm{~Hz} ; \sigma^{2}=0.476 \mathrm{~Hz}\right)$ ) (Fig. 4C). During avoidance behavior the relative nearest neighbor distance 240 is reduced compared to reef flat schooling behavior from $2.03 \pm 0.169 \mathrm{SL}(n=37)$ to $1.42 \pm 0.09 \mathrm{SL}$ $241(n=46)$ and an increased group cohesion becomes obvious in the synchronized escape movements 242 (Fig. 4D). 

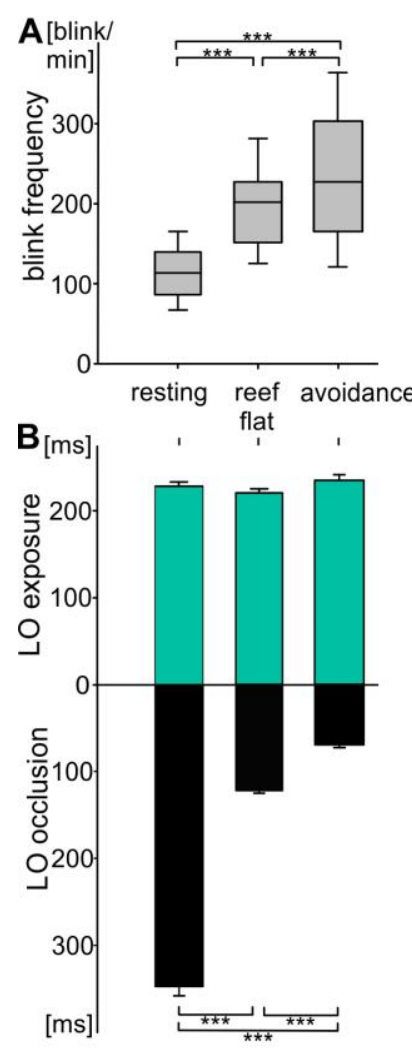
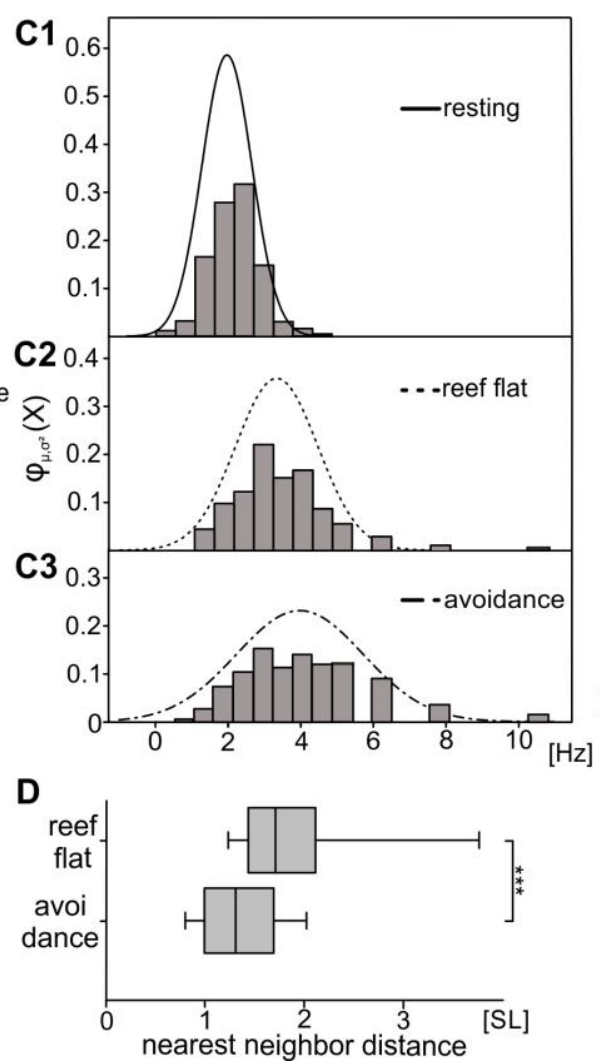

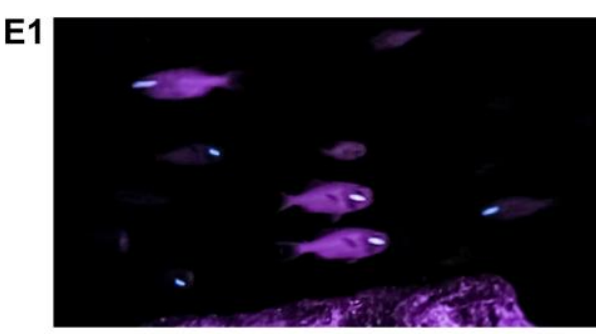

E2

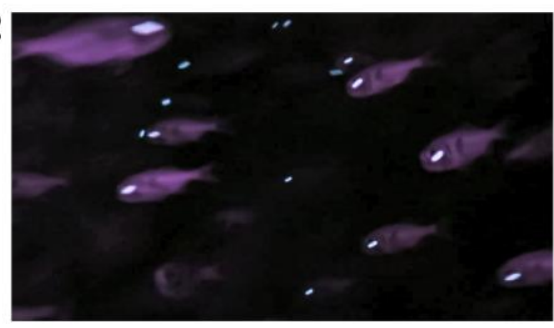

E3

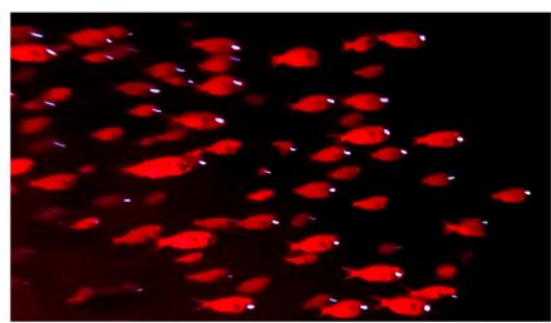

Figure 4. Analysis of the blinking behavior and nearest neighbor distance of schools of A. katoptron in Ambon, Maluku, Indonesia.

The behavior of $A$. katoptron was analyzed for three conditions: in a cave during the day, during the night at the reef flat close to the cave and during avoidance behavior in the night.

(A) Analysis of blink frequencies of A. katoptron in the cave, at the reef flat and during avoidance. Blink frequencies were calculated by analyzing alternating light organ exposition and occlusion (cave $n=709$; reef flat $n=444$ and avoidance $n=478$ ).

(B) Mean light organ exposure and occlusion ( \pm SEM) of $A$. katoptron in the cave (open $n=823$; closed $n=761$ ), at the reef flat (open $n=502$; closed $n=445$ ) and during avoidance (open $n=516$; closed $n=478$ ). Upper lines refer to stimulation as seen in (A).

(C) Relative distribution of blink frequencies of $A$. katoptron observed while resting in the cave (C1), at the reef flat (C2) and during avoidance (C3). Bars represent histogram with bin size of $0.6 \mathrm{~Hz}$. Distribution was fitted with normal (Gaussian) distribution (cave, $X\left(\mu=1.96, \sigma^{2}=0.476\right)$; reef flat, $X\left(\mu=3,33, \sigma^{2}=1.278\right)$; avoidance, $X$ $\left.\left(\mu=3.97, \sigma^{2}=3.062\right)\right)$.

(D) Analysis of the distance between specimen of A. katoptron on the reef flat and during avoidance. Screenshots of recordings were taken before $(n=37)$ and during avoidance reaction $(n=46)$ and analyzed. Avoidance was triggered by illumination of schooling A. katoptron with red diving torches. Distance is given as standard length (SL).

(E) Example still images of the videos of $A$. katoptron schooling during day in the cave (E1), during the night on the reef flat (E2) and during avoidance behavior in the night (E3). 


\section{Discussion}

In this study we found that variation in blink frequencies of the bioluminescent splitfin flashlight fish Anomalops katoptron is used for intraspecific communication important for schooling behavior.

Schools of $A$. katoptron can be observed at dark and moonless nights at the water surface in the Indo-Pacific. A. katoptron emit short bioluminescent light pulses using specialized light organs situated under the eye during schooling ${ }^{8,13}$. These subocular light organs are densely packed with bioluminescent, symbiotic bacteria (Candidatus photodesmus katoptron), which continuously produce bioluminescent light ${ }^{14-16}$. The fish disrupts light emission by a downward rotation of the light organ. Thus, exposure and occlusion of the light organ can produce specific blink frequencies ${ }^{45}$. We found that adjustment of the blink frequencies of $A$. katoptron depends on variations within the occlusion and not the exposure of the light organ while schooling. Light organ exposure is comparable to previous laboratory $\left(383 \mathrm{~ms} ;{ }^{8}\right)$ and field $\left(166 \mathrm{~ms} ;{ }^{13}\right)$ studies. In comparison longer flash durations of $400 \mathrm{~ms}$ in Lampanyctus niger ${ }^{42}$ and 1000-2000 ms in Gazza minuta ${ }^{44}$ have been described in other bioluminescent fish. Intraspecific recognition/communication is important to establish and maintain group structures ${ }^{46}$. Species-specific signals like visual cues ${ }^{30,47}$, motion ${ }^{48}$, auditory ${ }^{49}$ or electric signals ${ }^{37}$ have been described to be involved in this process. Visual cues are important to detect position and movement of conspecifics ${ }^{31}$ or predators ${ }^{50}$ in fish and become crucial in species that live under dim/low light conditions such as $A$. katoptron ${ }^{7}$. The bioluminescent light of $A$. katoptron is used for actively finding food and is most likely important for schooling behavior under dim light conditions and, therefore, for intraspecific communication ${ }^{8,13}$. In our study we showed that $A$. katoptron follows moving LED light pulses and that the swimming speed is adjusted to the moving light. The speed of the moving LEDs ( $200 \mathrm{~ms}$ off-time; travel speed of light: $0.58 \mathrm{~m} / \mathrm{s}$ ) potentially exceeded the mean swimming speeds of $A$. katoptron $(0,285 \pm 0.013 \mathrm{~m} / \mathrm{s})$, since individuals could follow the moving LEDs at lower moving speed more precisely. Mean swimming speeds depend on various factors such as body size, tail beat frequency, scale types or hydrodynamic effects ${ }^{51}$. The mean swimming speed of A. katoptron was estimated to 3,5 BL/s (body length per second), which correlates with other marine species $^{24,52,53}$

We also analyzed the blinking behavior of $A$. katoptron. We found that for intraspecific recognition A. katoptron only uses information of the blinking light and not the body shape, since we did not detect differences in the blink behavior when we used LEDs or LEDs implanted within a fish dummy. We also found that higher light intensities of the LEDs induced lower blink frequencies of 
because the higher intensity light penetrates further through water and could be received as a closer schooling neighbor. We measured for the first time the maximal light intensity of light emitted by the light organ from A. katoptron which was at $0.27 \mu \mathrm{W}$ at $510 \mathrm{~nm}$ wavelength. The retina of A. katoptron has also the maximal light sensitivity in this range ${ }^{19}$. Light intensity could potentially represent fitness levels of individuals as $A$. katoptron tend to loose luminescence due to starvation ${ }^{54}$. Other fish species prefer to shoal with healthy conspecifics ${ }^{55,56}$. Schooling fish tend to show consistency in their appearance (confusion effect) ${ }^{29,57}$ and often do not show a sexual dimorphism including flashlight fish (but also see pony fish Gazza minuta) ${ }^{44,58}$.

The most important result of our study is that blink frequencies adjusted by light organ occlusion determine nearest neighbor distance. We suggest that light organ exposure and occlusion are alternating signals for attraction and repulsion in defining nearest neighbor distance in schooling A. katoptron. Nearest neighbor distance is a key factor in schooling fish and determines group cohesion ${ }^{59}$. The shape of a school is the integration of individual responses on surrounding ecological factors ${ }^{46}$. Thereby intraspecific signals such as bioluminescent blinks in flashlight fish need to be included. In ponyfish (Leiognathidae) luminescent flashes have been proposed to function in spacing between individuals and keeping the school together ${ }^{60}$. Here we present a mechanism that potentially drives the opposing forces of attraction and repulsion in bioluminescent fish.

To gain an understanding of how blinking behavior is used for intraspecific communication in the field, we analyzed the blinking behavior of schools of $A$. katoptron in a cave during the day and at the entrance of the cave during the night in Ambon, Malukku, Indonesia using infrared recordings. We found that the blink frequency decreased during the day in comparison to blink behavior at night. Blinking behavior increased when fish were illuminated with a red torch, which caused an avoidance behavior and a reduction in the nearest neighbor distance. This became obvious by a change from a broad to a dense school formation. Increased blink frequencies seem to be correlated with stress reactions, since we observed increased blink frequencies when A. katoptron were isolated in the laboratory. Increase in blink frequencies are also known from Photoblepharon steinitzii, when artificial intruders have been introduced into their territory ${ }^{12}$.

In conclusion, our study shows that Anomalops katoptron uses intraspecific, bioluminescent blink signals for communication of nearest neighbor distance important for group cohesion during schooling. 
332

\section{Methods}

\section{Recordings in the Laboratory}

\section{Maintenance of $A$. katoptron}

A group of splitfin flashlight fish A. katoptron was kept in a reef tank $(600 \mathrm{l} ; 135 \mathrm{~cm}$ length $\mathrm{x} 66 \mathrm{~cm}$ depth $\times 70 \mathrm{~cm}$ height). All specimens were obtained from a commercial wholesaler (De Jong Marinelife, Netherlands) and captured at the Cebu Islands (Philippines). For at least six weeks prior to the experiments $A$. katoptron were kept in the reef tank (temperature: $26^{\circ}-27^{\circ} \mathrm{C}$; salinity: $36 \%$; $12 \mathrm{~h}$ day and night cycle). The housing tank (600 l; $135 \mathrm{~cm}$ length $\times 66 \mathrm{~cm}$ depth $\times 70 \mathrm{~cm}$ height) was connected to an additional filter sump containing phosphate absorber, activated carbon, protein skimmer and an UV-sterilizer. The specimens were fed once a day with defrosted zooplankton (mysid shrimps), fish/lobster eggs and fine minced, defrosted salmon. Feeding occurs under dim red light to obtain visual observation on fitness levels of individuals. Information on age is missing because all individuals were wild collected imports. No visible differences between females and males were observed. Individuals were identified by size, slight differences in pigmentation and intensity of light organs.

\section{Artificial light organs and fish dummies}

A fish dummy with artificial light organs was made of black silicon (food safe silicon MM720 FG; Silikonfabrik; Germany). The shape of the dummy was modelled based on several photographs and had a total length (TL) of $101 \mathrm{~mm}$. At the anterior-ventral side an oval shaped opening was cut out of the dummy. The cutout was equipped with a LED to imitate the light organs of $A$. katoptron. The LED was connected to an Arduino microcontroller (Arduino Mega 2560; Arduino; Italy). Resistors between LED and microcontroller were set to an output flow of $1 \mathrm{~mA}$. The LED was waterproof glued (2-K epoxy glue; UHU; Germany) in an acrylic glass tube (length $15 \mathrm{~mm}$; external diameter $7 \mathrm{~mm}$ ) painted with flat white acrylic paint (Revell; Germany) to diffuse the LED light. The acrylic glass inlet was mounted in the fish dummy (artificial light organ length: $10 \mathrm{~mm}$; height: $7 \mathrm{~mm}$ ). The LED (Nichia $3 \mathrm{~mm}$ LED cyan $14.720 \mathrm{mcd}$; Winger; Germany) had a peak wavelength at $500 \mathrm{~nm}$ and was adjusted to the mean light emittance of $0.23 \mu \mathrm{W} / \mathrm{nm}$ of $A$. katoptron's light organs (Fig. S2). Intensities of light organs ( $n=5)$ and LEDs were measured with a spectrometer (Ocean Optics; Flame; United States).

The microcontroller was set to control artificial light organs in relation to on- and off-times. The control software was written with Matlab (Matlab 2015r) and the open source Arduino software (Arduino 1.8.10). LED light intensities were adjusted by using a pulse width modulation (PWM). 
Recordings in the experimental tank and arena experiments (see below) were made with an infrared (IR) sensitive camcorder (Sony HDR-CX 730; 6.3 mm CMOS-Sensor, 24.1 megapixel, video resolution $1920 \times 1080$ pix, $50 \mathrm{fps}$ ) mounted on a custom made aluminum stand. Video files were converted to audio video interleave-format (.avi) with a resolution of $1080 \times 720$ pix and $25 \mathrm{fps}$ using Adobe Premiere Elements 15 (Adobe; United States).

The recording tank was divided in the middle with a grey PVC plate. Specimens could switch sides through a lockable slide door $(20 \times 20 \mathrm{~cm})$. One of the sides contained daytime shelters made from clay tiles whilst the other half was blank except for a flow pump (EcoDrift 4.2; Aqua Medic; Germany). Specimen of $A$. katoptron ( $\mathrm{n}=5)$ were isolated on the blank side $(60 \mathrm{~cm} \times 60 \mathrm{~cm} \times 60 \mathrm{~cm}$ ) of the experimental tank and habituated for five minutes prior to the experiment.

The fish dummy was placed in the middle of the recording tank. Each light stimulus was presented for a duration of five minutes. Every stimulus presentation was repeated five times. Here we chose equal distributed on- and off times in LED timing with $0.5 \mathrm{~Hz}$ ( $1 \mathrm{~s}$ on- and $1 \mathrm{~s}$ off-time), $1 \mathrm{~Hz}$ ( $0.5 \mathrm{~s}$ onand $0.5 \mathrm{~s}$ off-time) and $2 \mathrm{~Hz}$ ( $0.25 \mathrm{~s}$ on- and $0.25 \mathrm{~s}$ off-time). Previous laboratory experiments showed a nearly equal distribution of light organ exposure and occlusion times while swimming in a group ${ }^{8}$. We performed a control experiment with turned off artificial light organs (DC, dark control) implemented in the dummy. The camera was mounted on a tripod in front of the tank. Two IR-lights each consisting of five high power LEDs with $860 \mathrm{~nm}$ peak wavelength (WEPIR1-S1 IR Power $1 \mathrm{~W}$, Winger Electronics $\mathrm{GmbH}$, Germany) were placed $10 \mathrm{~cm}$ above the tank.

In a second experiment, we analyzed the role of dummy (fish) shape and isolated light organ dummies on the behavior of $A$. katoptron ( $n=5$; same individuals used in the first experiment). Therefore, an isolated light organ dummy (LED as described above) was used during stimulation. We chose a light stimulation protocol of $1 \mathrm{~Hz}(0.5 \mathrm{~s}$ on- and $0.5 \mathrm{~s}$ off-times) because this stimulation had the strongest effect on blink frequencies of isolated specimen. In the next step we analyzed differences in blink frequencies for two specimens with intact light organs as well as one specimen with intact and one with non-glowing light organs to test orientation of $A$. katoptron towards light organs of conspecifics (Fig. S1). In this case, we performed a frame by frame analysis (video analysis software; Vidana 1.0) of distances between individuals. All stimuli were presented for five minutes in a pseudo-randomized order. Five repetitions were performed for each specimen. 
frequencies and light organ exposure-/occlusion-times were analyzed with Excel (Excel 2016). Successive exposure and occlusion events were summarized as blink event.

Trajectories were analyzed with the video analysis software Vidana 1.0. Two rectangles of interest (ROI) were defined to analyze the swimming profiles in A. katoptron. As individuals could switch between the two sides of the tank amongst experiments, we defined the areas where occurrence was most likely. The area around the closed door was declared as "exit area". The area around the dummy placed in the middle was defined as "center".

Arena experiment 1: Nearest Neighbor Distance

404

405

406

407

408

409

410

411

Large-scale swimming profiles during presentation of a fish dummy with artificial light organs were analyzed in a circular arena with $120 \mathrm{~cm}$ diameter (Winipet Dogpool; China). Seawater from the housing tank was used to ensure equal parameters in water chemistry e.g. carbon hardness, nitrate and $\mathrm{pH}$ values. The arena was filled with approximately $170 \mathrm{I}$ seawater $(15 \mathrm{~cm}$ water level). Single specimen of $A$. katoptron ( $\mathrm{n}=10)$ were transferred to the arena using a hand net $(12.5 \mathrm{~cm} \times 10 \mathrm{~cm}$; Sera; Germany). Prior to the experiments fish were habituated for five minutes in the arena tank. A fish dummy with artificial light organs (as described above) was placed $7.5 \mathrm{~cm}$ over the tank bottom in the center of the arena. In this experiment artificial light organs were constantly glowing up for $300 \mathrm{~ms}$ whereas off-times changed. The occlusion of artificial light organs was adjusted to $200 \mathrm{~ms}$ ( $2 \mathrm{~Hz}$ stimulation) or $500 \mathrm{~ms}(1.25 \mathrm{~Hz}$ stimulation) but consistent during one trial. We additionally performed a control experiment without light emitted by the dummy (DC, dark control). Stimuli were randomly presented for 30 seconds with six repetitions. Videos were recorded using an infrared (IR) sensitive Sony HDR-CX730E camcorder (1920 x 1080 pix; $50 \mathrm{fps})$ mounted above the arena on a custom made stand. Two IR-lights each consisting of five high power LEDs (WEPIR1-S1 IR Power 1 W, Winger Electronics $\mathrm{GmbH}$, Germany) were placed besides the arena mounted on custom made holding devices. Tracking profiles of $A$. katoptron were analyzed using the video analysis software Vidana 1.0. Heat maps were generated in Matlab (Matlab R2015b). Here we summarized equal positions of standardized tracking profiles to estimate relative occurrences of $A$. katoptron.

\section{Arena experiment 2: Swimming Speed}

To validate the following behavior and maximum swimming speeds of $A$. katoptron we established an array of LEDs that were rotated consecutively to simulate a moving light organ. In this experiment, 13 LEDs were wall-mounted in an equal distributed distance (specifications circular arena see above). Angle between LEDs was set to $27.69^{\circ}$. The LEDs were placed on a water level of $7.5 \mathrm{~cm}$. On-times of LEDs was permanently set to 300 ms while interval among the light onset between two LEDs was 
changed. During one trial intervals between two LEDs were set to $200 \mathrm{~ms}$ or $500 \mathrm{~ms}$. LEDs were triggered clockwise or counter clockwise in a pseudo randomized order. A dark control (DC) experiment without light stimulation was performed to avoid potential orientation cues from the periphery of the experimental arena. Handling of A. katoptron as described under Arena Experiment 1.

Experiments in single specimens of $A$. katoptron $(n=9)$ were started after five minutes habituation time in the arena. Each stimulus was presented for $60 \mathrm{~s}$. Specimens were tested five times for each stimulus. Movement profiles, swimming speed and radius of $A$. katoptron were analyzed using the video analysis software Vidana 1.0. Relative movement directions were estimated with Solomon Coder (Version 19.08.02). We estimated the precision of $A$. katoptron to follow moving light sources on a defined radius (distance between individuals and center of the tank). For each stimulation (1.25 Hz, $2 \mathrm{~Hz} \& D C$ ) we calculated the probability of individuals to move with the direction of light (Fig. S3). During dark control (DC) isolated individuals were moving clockwise $(0.41 \pm 0.034)$, counterclockwise $(0.44 \pm 0.034)$ or without a defined movement direction, declared as other $(0.15 \pm 0.001)$. Isolated specimen were following the counter- or clockwise rotating LED light to $0.724 \pm 0.034$ (200 ms off-times) and $0.78 \pm 0.031$ (500 ms off-times). Subsequently we multiplied the probability to follow the rotating light or the highest value in case of the dark control (DC) with the radius to estimate the precision.

\section{Field Recordings}

Field recordings were made alongside two different Islands in the Banda Sea (Indonesia). Several schools of $A$. katoptron were observed via snorkeling on the shallow reef flats of Pulau Gunung Api, Banda Islands (4³0'20.2"S $\left.129^{\circ} 52^{\prime} 49.7^{\prime \prime} \mathrm{E}\right)$. Recordings on the Banda Islands were made after sunset on $1^{\text {st }}-4^{\text {th }}$ of March 2019 prior new moon $\left(7^{\text {th }}\right.$ of March 2019) and the $26^{\text {th }}$ of March 2019 (five days after full moon). Recordings on the Banda Islands were made before moonrise. Schools of A. katoptron occur from deeper water (> $60 \mathrm{~m}$; pers. obs.) or caves during dark and moonless nights on the shallow reef flats of Gunung Api. The observation site in Ambon ( $\left.3^{\circ} 44^{\prime} 54.5^{\prime \prime S} 128^{\circ} 12^{\prime} 43.3^{\prime \prime} \mathrm{E}\right)$ was quite different and recordings made while scuba diving. Schools were hiding throughout the day in a large cave (main chamber dimensions approximately $10 \times 5 \times 6 \mathrm{~m}$ ) with many small crevices that were not accessible. The cave entrance was in approximately $6 \mathrm{~m}$ depth beneath the water surface depending on the tide. Field recordings in Ambon were made between $19^{\text {th }}-20^{\text {th }}$ of March 2019 before full moon (21 $1^{\text {st }}$ of March) and on 17. April 2019 before full moon (19 th $^{\text {th }}$ April 2019). During the day, recordings were made in the cave and continued while sunset when schools of $A$. katoptron emerged through the cave exit. After several minutes schools accumulated in front of the cave where overhanging rock casts a shadow of the moonlight. This was leading to a restricted area of 
movement. We defined three different recording conditions to analyze the behavior in A. katoptron: 1. "resting" (recordings in the cave during day without illumination); 2. "schooling" (outside cave or on reef flat during night without illumination) and 3. "avoidance" (avoidance elicited by red diving torch during night).

Video recordings were made with a modified camera (Canon Powershot G1X Mark 2; APS-C-Sensor; 24 megapixel; video resolution: $1920 \times 1080$ pix; $30 \mathrm{fps})$. The infrared filter in front of the camera sensor was removed to obtain infrared sensitivity. The camera was placed in an underwater housing (Canon WP-DC53). Two custom made underwater infrared lights mounted on both sides of the underwater housing were used two illuminate schools of $A$. katoptron in the cave and open water. Each IR-light consisted of five high power IR-LED with $860 \mathrm{~nm}$ peak wavelength (WEPIR1-S1 IR Power $1 \mathrm{~W}$, Winger Electronics $\mathrm{GmbH}$, Germany).

A LED diving torch with red light (300 lumen red light; $634 \mathrm{~nm}$ peak wavelength; Codylight 1500; Codygear; Germany) was switched on while the school was swimming outside the cave or on the reef flat to elicit avoidance reactions. "Avoidance" was triggered pseudorandomized when specimen were within a range of approximately $1.5 \mathrm{~m}$ to ensure sufficient illumination with IR-lights. The red light was switched on until the school disappeared from view. After A. katoptron gathered outside the cave a minimum of two minutes was waited before red torches were repeatedly turned on.

We recorded $n=5$ video sequences (709 blink events in 326 seconds) for "resting" in the cave, $n=8$ video sequences (444 blink events in 272 seconds) during "schooling" on the reef flat and $n=5$ video sequences ( 478 blink events in 40 seconds) in case of "avoidance".

Relative distances between school members were estimated via ImageJ (ImageJ 1.50i; National Institute of Health). We compared single screenshots taken from video sequences of schooling A. katoptron without $(n=37)$ and with illumination with red torches $(n=46)$. We defined relative length (SL) of at least one individual as reference to estimate the relative distance between members of the school. We chose distances between individuals that seemed to be neighbors as twodimensional recording could not provide a distinct spatial distribution (see also Fig. S4).

Blink frequencies were analyzed using the video analysis software Vidana 1.0. Specimens of A. katoptron were marked after the first occurrence in the video sequence and the behavior was analyzed until the specimen disappeared in the recording sequence. Exposure and Occlusion of light organs was analyzed frame by frame per individual occurrence. Mean values were summarized for all analyzed parameters. Blink frequencies were estimated based on pairs of light organ exposure and occlusion times. We created a Gaussian distribution (Fig. 4) using the internal SigmaPlot function (SigmaPlot 12.0) to show the distribution of blink frequencies during three situations in the field 
496 ("resting", "schooling" \& "avoidance"). Additionally, we created histograms with the internal Matlab

497 function (Matlab R2015b). Here we chose a bin size of 0,6 Hz.

\section{$498 \quad$ Statistical Analysis}

499 SigmaPlot 12.0 was used to evaluate statistical differences between test groups. Differences in blink

500 frequencies, exposure and occlusion times of light organs, distance between individuals, swimming

501 speed and spatial distribution were compared using a repeated measurement one-way ANOVA and

502 Holm-Sidak post hoc analysis. All values are reported as mean \pm SEM (standard error of mean).

503 Statistical significant values are reported as: ${ }^{*} p \leq 0.05,{ }^{* *} p \leq 0.01 ; * * p \leq 0.001$. 
504

505

506

507

508

509

510

511

512

513

514

515

516

517

518

519

520

521

522

523

\section{References}

1. Haddock, S. H. D., Moline, M. A. \& Case, J. F. Bioluminescence in the sea. Annual review of marine science $2,443-493 ; 10.1146 /$ annurev-marine-120308-081028 (2010).

2. Davis, M. P., Sparks, J. S. \& Smith, W. L. Repeated and Widespread Evolution of Bioluminescence in Marine Fishes. PLOS ONE 11, e0155154; 10.1371/journal.pone.0155154 (2016).

3. Bessho-Uehara, M. et al. Kleptoprotein bioluminescence: Parapriacanthus fish obtain luciferase from ostracod prey. Science advances 6, eaax4942; 10.1126/sciadv.aax4942 (2020).

4. Claes, J. M. \& Mallefet, J. Early development of bioluminescence suggests camouflage by counter-illumination in the velvet belly lantern shark Etmopterus spinax (Squaloidea: Etmopteridae). Journal of Fish Biology 73, 1337-1350; 10.1111/j.1095-8649.2008.02006.x (2008).

5. Harper, R. D. \& Case, J. F. Disruptive counterillumination and its anti-predatory value in the plainfish midshipman Porichthys notatus. Marine Biology 134, 529$540 ; 10.1007 / \mathrm{s} 002270050568$ (1999).

6. Herring, P. J. Sex with the lights on? A review of bioluminescent sexual dimorphism in the sea. J. Mar. Biol. Ass. 87, 829-842; 10.1017/S0025315407056433 (2007). 
7. Widder, E. A. Bioluminescence in the ocean: origins of biological, chemical, and ecological diversity. Science (New York, N.Y.) 328, 704-708; 10.1126/science.1174269 (2010).

8. Hellinger, J. et al. The Flashlight Fish Anomalops katoptron Uses Bioluminescent Light to Detect Prey in the Dark. PLOS ONE 12, e0170489; 10.1371/journal.pone.0170489 (2017).

9. Golani, D., Fricke, R. \& Appelbaum-Golani, B. Review of the genus Photoblepharon (Actinopterygii: Beryciformes: Anomalopidae). Acta Ichthyol. Piscat. 49, 33-41; 10.3750/AIEP/02530 (2019).

10.Ho, H.-C. \& Johnson, G. D. Protoblepharon mccoskeri, a new flashlight fish from eastern Taiwan (Teleostei: Anomalopidae). Zootaxa, 77-87; 10.11646/zootaxa.3479.1.5 (2012).

11. Morin, J. G. et al. Light for All Reasons: Versatility in the Behavioral Repertoire of the Flashlight Fish. Science 190, 74-76; 10.1126/science.190.4209.74 (1975).

12. Hellinger, J. et al. Analysis of the Territorial Aggressive Behavior of the Bioluminescent Flashlight Fish Photoblepharon steinitzi in the Red Sea. Front. Mar. Sci. 7, 431; 10.3389/fmars.2020.00078 (2020).

13. Gruber, D. F. et al. Bioluminescent flashes drive nighttime schooling behavior and synchronized swimming dynamics in flashlight fish. PLOS ONE 14, e0219852; 10.1371/journal.pone.0219852 (2019). 
14. Hendry, T. A., Wet, J. R. de \& Dunlap, P. V. Genomic signatures of obligate host dependence in the luminous bacterial symbiont of a vertebrate. Environmental microbiology 16, 2611-2622; 10.1111/1462-2920.12302 (2014).

15. Hendry, T. A., Wet, J. R. de, Dougan, K. E. \& Dunlap, P. V. Genome Evolution in the Obligate but Environmentally Active Luminous Symbionts of Flashlight Fish. Genome biology and evolution 8, 2203-2213; 10.1093/gbe/evw161 (2016).

16. Haneda, Y. \& Tsuji, F. I. Light production in the luminous fishes Photoblepharon and Anomalops from the Banda Islands. Science (New York, N.Y.) 173, 143-145; 10.1126/science.173.3992.143 (1971).

17. Bassot, J.-M. in Bioluminescence in Progress, edited by F. H. Johnson \& Y. Haneda (Princeton University Press1966), pp. 557-610.

18. Watson, M., Thurston, E. L. \& Nicol, J. A. C. Reflectors in the Light Organ of Anomalops (Anomalopidae, Teleostei). Proceedings of the Royal Society of London. Series B, Biological Sciences 202, 339-351 (1978).

19. Mark, M. D. et al. Visual tuning in the flashlight fish Anomalops katoptron to detect blue, bioluminescent light. PLOS ONE 13, e0198765; 10.1371/journal.pone.0198765 (2018).

20. Howland, H. C., Murphy, C. J. \& McCosker, J. E. Detection of eyeshine by flashlight fishes of the family anomalopidae. Vision Research 32, 765-769; 10.1016/00426989(92)90191-K (1992). 
564

565

566

567

568

569

570

571

572

573

574

575

576

577

578

579

580

21. McCosker, J. E. \& Rosenblatt, R. H. Notes on the biology, taxonomy, and distribution of flashlight fishes (Beryciformes: Anomalopidae). Jap. Jour. Ich. 34, 157-164; 10.1007/BF02912410 (1987).

22.Parrish, J. K., Viscido, S. V. \& Grünbaum, D. Self-organized fish schools: an examination of emergent properties. The Biological bulletin 202, 296-305; $10.2307 / 1543482$ (2002).

23. Pitcher, T. J. (ed.). Behaviour of teleost fishes (Chapman \& Hall, London, 1993).

24. Helfman, G. S., Collette, B. B., Facey, D. E. \& Bowen, B. W. The diversity of fishes. Biology, evolution, and ecology. 2nd ed. (Wiley-Blackwell, Oxford, 2009).

25. McLean, S., Persson, A., Norin, T. \& Killen, S. S. Metabolic Costs of Feeding Predictively Alter the Spatial Distribution of Individuals in Fish Schools. Current Biology 28, 1144-1149.e4; 10.1016/j.cub.2018.02.043 (2018).

26. Pitcher, T. J., Magurran, A. E. \& Winfield, I. J. Fish in larger shoals find food faster. Behavioral Ecology and Sociobiology 10, 149-151; 10.1007/BF00300175 (1982).

27. Ioannou, C. C., Guttal, V. \& Couzin, I. D. Predatory fish select for coordinated collective motion in virtual prey. Science (New York, N.Y.) 337, 1212-1215; 10.1126/science.1218919 (2012).

28.Turner, G. F. \& Pitcher, T. J. Attack Abatement: A Model for Group Protection by Combined Avoidance and Dilution. The American Naturalist 128, 228-240; 10.1086/284556 (1986). 
584

585

586

587

588

589

590

591

592

593

594

595

596

597

598

599

600

601

602

603

29. Landeau, L. \& Terborgh, J. Oddity and the 'confusion effect' in predation. Animal Behaviour 34, 1372-1380; 10.1016/S0003-3472(86)80208-1 (1986).

30. Kowalko, J. E. et al. Loss of Schooling Behavior in Cavefish through SightDependent and Sight-Independent Mechanisms. Current Biology 23, 1874-1883; 10.1016/j.cub.2013.07.056 (2013).

31.Partridge, B. L. \& Pitcher, T. J. The sensory basis of fish schools: Relative roles of lateral line and vision. J. Comp. Physiol. 135, 315-325; 10.1007/BF00657647 (1980).

32. Herbert-Read, J. E. et al. How predation shapes the social interaction rules of shoaling fish. Proceedings. Biological sciences 284; 10.1098/rspb.2017.1126 (2017).

33. Bierbach, D. et al. Using a robotic fish to investigate individual differences in social responsiveness in the guppy. Royal Society open science 5, 181026; 10.1098/rsos.181026 (2018).

34.Berdahl, A., Torney, C. J., Ioannou, C. C., Faria, J. J. \& Couzin, I. D. Emergent sensing of complex environments by mobile animal groups. Science (New York, N.Y.) 339, 574-576; 10.1126/science.1225883 (2013).

35. Sosna, M. M. G. et al. Individual and collective encoding of risk in animal groups. Proceedings of the National Academy of Sciences of the United States of America 116, 20556-20561; 10.1073/pnas.1905585116 (2019). 
604

605

606

607

608

609

610

611

612

613

614

615

616

617

618

619

620

621

622

36. Kunz, H. \& Hemelrijk, C. K. Artificial fish schools: collective effects of school size, body size, and body form. Artificial life 9, 237-253;

$10.1162 / 106454603322392451$ (2003).

37. Worm, M. et al. Evidence for mutual allocation of social attention through interactive signaling in a mormyrid weakly electric fish. Proceedings of the National Academy of Sciences of the United States of America 115, 6852-6857; 10.1073/pnas.1801283115 (2018).

38. Marras, S., Batty, R. S. \& Domenici, P. Information transfer and antipredator maneuvers in schooling herring. Adaptive Behavior 20, 44-56; 10.1177/1059712311426799 (2012).

39. Cohen, A. C. \& Morin, J. G. It's All About Sex: Bioluminescent Courtship Displays, Morphological Variation and Sexual Selection in Two New Genera of Caribbean Ostracodes. Journal of Crustacean Biology 30, 56-67; 10.1651/09-3170.1 (2010).

40. Rivers, T. J. \& Morin, J. G. Complex sexual courtship displays by luminescent male marine ostracods. The Journal of experimental biology 211, 2252-2262; 10.1242/jeb.011130 (2008).

41. Widder, E. A., Latz, M. I., Herring, P. J. \& Case, J. F. Far red bioluminescence from two deep-sea fishes. Science (New York, N.Y.) 225, 512-514; 10.1126/science.225.4661.512 (1984). 
42. Mensinger, A. F. \& Case, J. F. Luminescent properties of deep sea fish. Journal of Experimental Marine Biology and Ecology 144, 1-15; 10.1016/00220981(90)90015-5 (1990).

43.Sasaki, A. et al. Field Evidence for Bioluminescent Signaling in the Pony Fish, Leiognathus elongatus. Environmental Biology of Fishes 66, 307-311; 10.1023/A:1023959123422 (2003).

44. McFall-Ngai, M. J. \& Dunlap, P. V. Three new modes of luminescence in the leiognathid fish Gazza minuta: Discrete projected luminescence, ventral body flash, and buccal luminescence. Marine Biology 73, 227-237; 10.1007/BF00392247 (1983).

45.Johnson, G. D. \& Rosenblatt, R. H. Mechanisms of light organ occlusion in flashlight fishes, family Anomalopidae (Teleostei: Beryciformes), and the evolution of the group. Zoological Journal of the Linnean Society 94, 65-96; 10.1111/j.10963642.1988.tb00882.x (1988).

46. Herbert-Read, J. E. et al. Inferring the rules of interaction of shoaling fish. Proceedings of the National Academy of Sciences of the United States of America 108, 18726-18731; 10.1073/pnas.1109355108 (2011).

47.Siebeck, U. E., Parker, A. N., Sprenger, D., Mäthger, L. M. \& Wallis, G. A species of reef fish that uses ultraviolet patterns for covert face recognition. Current biology : CB 20, 407-410; 10.1016/j.cub.2009.12.047 (2010). 
643

644

645

646

647

648

649

650

651

652

653

654

655

656

657

658

659

660

661

662

663

48. Larsch, J. \& Baier, H. Biological Motion as an Innate Perceptual Mechanism Driving Social Affiliation. Current Biology 28, 3523-3532.e4; 10.1016/j.cub.2018.09.014 (2018).

49. Kasumyan, A. O. Acoustic signaling in fish. J. Ichthyol. 49, 963-1020; 10.1134/S0032945209110010 (2009).

50.Santon, M. et al. Redirection of ambient light improves predator detection in a diurnal fish. Proceedings. Biological sciences 287, 20192292; 10.1098/rspb.2019.2292 (2020).

51. Bainbridge, R. The Speed of Swimming of Fish as Related to Size and to the Frequency and Amplitude of the Tail Beat. Journal of Experimental Biology 35, 109 (1958).

52.Videler, J. J. \& Wardle, C. S. Fish swimming stride by stride: speed limits and endurance. Rev Fish Biol Fisheries 1, 23-40; 10.1007/BF00042660 (1991).

53. Ware, D. M. Bioenergetics of Pelagic Fish: Theoretical Change in Swimming Speed and Ration with Body Size. J. Fish. Res. Bd. Can. 35, 220-228; 10.1139/f78-036 (1978).

54. Meyer-Rochow, V. B. Loss of bioluminescence inAnomalops katoptron due to starvation. Experientia 32, 1175-1176; 10.1007/BF01927610 (1976).

55. Barber, I., Downey, L. C. \& Braithwaite, V. A. Parasitism, oddity and the mechanism of shoal choice. Journal of Fish Biology 53, 1365-1368; 10.1111/j.1095-8649.1998.tb00256.x (1998). 
664

665

666

667

668

669

670

671

672

673

674

675

676

677

678

679
56. Ward, A. J. W., Duff, A. J., Krause, J. \& Barber, I. Shoaling behaviour of sticklebacks infected with the microsporidian parasite, Glugea anomala. Environ Biol Fish 72, $155-160 ; 10.1007 / s 10641-004-9078-1(2005)$.

57. Theodorakis, C. W. Size segregation and the effects of oddity on predation risk in minnow schools. Animal Behaviour 38, 496-502; 10.1016/S0003-3472(89)80042-9 (1989).

58.Steche, O. Die Leuchtorgane von Anomalops katoptron und Photoblepharon palpebratus, zwei Oberflächenfischen aus dem malayischen Archipel: Ein Beitrag zur Anatomie und Physiologie der Leuchtorgane der Fische (Z Wiss Zool., 1909).

59. Parrish, J. K. \& Edelstein-Keshet, L. Complexity, pattern, and evolutionary tradeoffs in animal aggregation. Science (New York, N.Y.) 284, 99-101; 10.1126/science.284.5411.99 (1999).

60. Woodland, D. J., Cabanban, A. S., Taylor, V. M. \& Taylor, R. J. A synchronized rhythmic flashing light display by schooling Leiognathus splendens (Leiognathidae : Perciformes). Mar. Freshwater Res. 53, 159; 10.1071/MF01157 (2002). 
A1

Isolated
(ISO)
Dummy

$\left(\mathrm{DU}^{-}\right)$

A. katoptron degenerated LO

(LO')
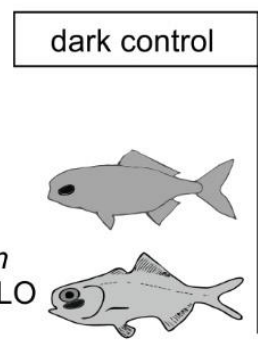

light stimulation
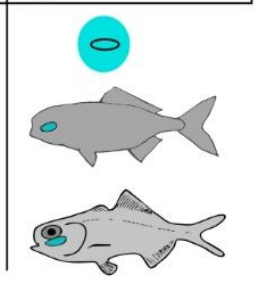

LED

Dummy

$\left(\mathrm{DU}^{+}\right)$

A. katoptron intact LO

(LO+)

\section{A2}
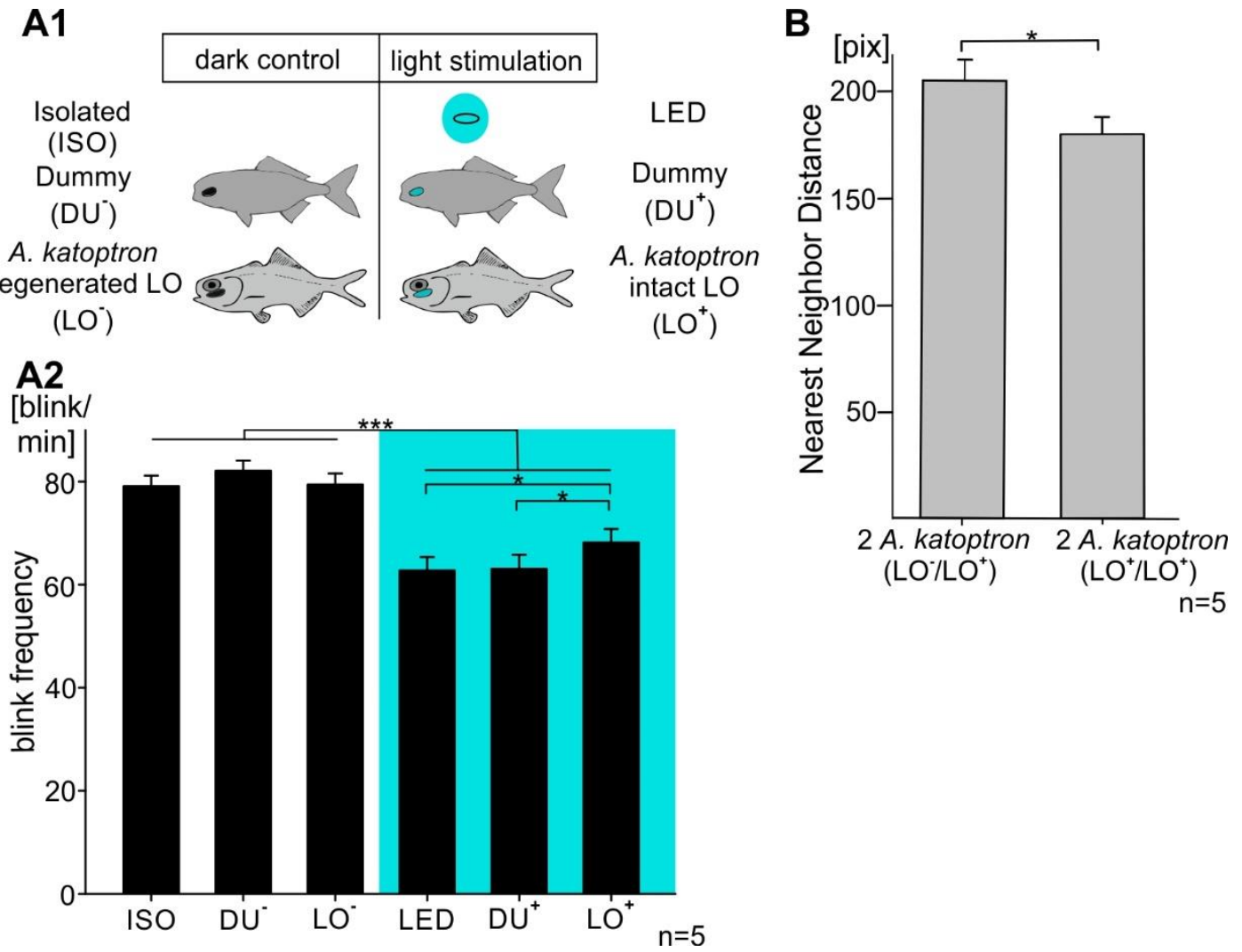

682

683

684

685

686

687

688

689

690

691

692

693

694

695

696

697

698

Figure S1. Blink behavior of A. katoptron during exposure to different artificial light stimuli and their orientation towards conspecifics.

(A1) Natural and artificial light stimulation used in the experiments to investigate the blink behavior of A. kataptron. Two different types (light stimulation or dark controls) were presented to isolated individuals, i.e. an isolated LED and a fish dummy, equipped with a LED at the position of the light organ. Artificial lights had the same size, intensities and emitted $1 \mathrm{~Hz}$ light pulses (equally distributed LED on- and off- times). Experiments were repeated 5 times with five individuals independently and values are given as mean ( \pm SEM). The behavioral responses to the artificial lights were compared to responses to $A$. kataptron with an intact light organ $\left(\mathrm{LO}^{+}\right)$and a degenerated light organ ( $\left.\mathrm{LO}^{-}\right)$.

(A2) Blink frequencies of isolated A. katoptron during exposure to dark controls (left, white background) and light stimulation (right, blue background). Blink frequencies were reduced in the presence of light-stimuli. LED and the fish dummy light stimuli reduced the blink frequency more than the conspecifics.

(B) A. katoptron show a closer mean $( \pm \mathrm{SEM})$ orientation towards its neighbors when both specimen display intact light organs $\left(\mathrm{LO}^{+} / \mathrm{LO}^{+}\right)$.

Statistical significance was evaluated with RM ANOVA.

Significance values are reported as: ${ }^{*} \mathrm{p}<0.05,{ }^{*} \mathrm{p}<0.01,{ }^{* * *} \mathrm{p}<0.001$. Error bars indicate SEM. 
699
A

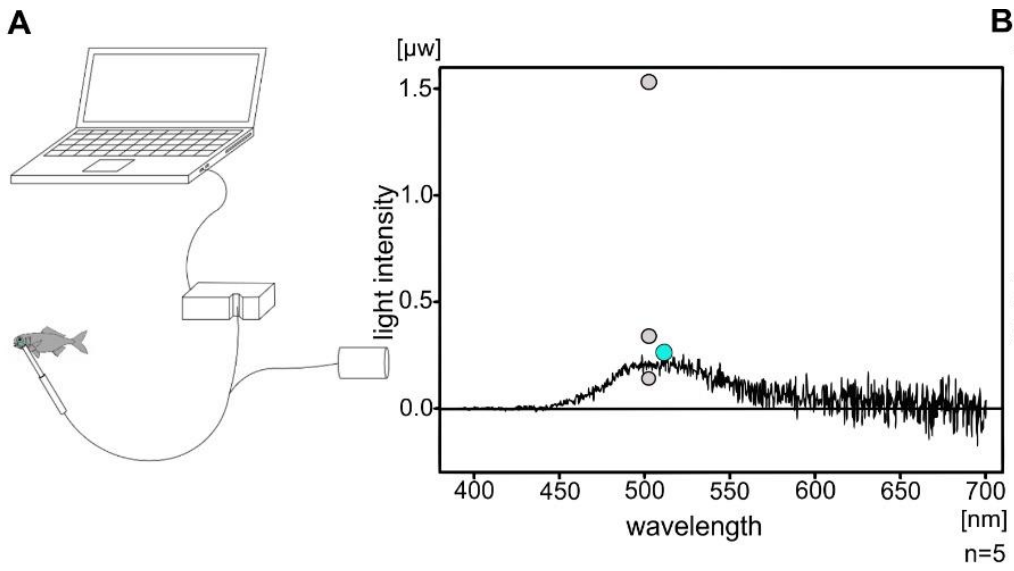

$\mathbf{B}_{[\mathrm{b}}$

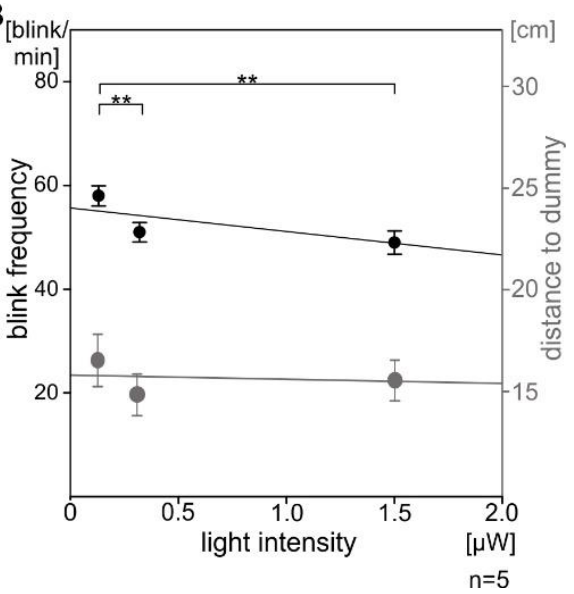

Figure S2. Spectrometric measurements of the light intensities emitted by light organs of A. katoptron in comparison to LEDs and the dependency of blinking behavior on different light intensities.

(A) Spectrometric measurement of the light organ $(n=5)$ intensity of $A$. kataptron in comparison to LED light. Diagram of the experimental setup for the spectrometric measurements (left). Intensities were measured with a spectrometer (Flame S-UV-VIS-ES, Ocean Optics,USA). The spectroscopic probe was placed in front of the light organs of fixed individuals. Each light organ was measured five times and mean intensity averaged. Example trace of the spectrometric measurement of the light intensities emitted by the light organs measured in the range between $400-700 \mathrm{~nm}$ wavelength (right). Gray dots indicate three different LED intensities of $0.133,0.328 \& 1.523 \mu \mathrm{W}$ at $504 \mathrm{~nm}$ wavelength, which were presented to isolated flashlight fish (A. katoptron) to investigate impact on blink frequency. The green dot indicates the maximum intensity observed in A. katoptron ( $0.27 \mu \mathrm{W}$ at $510 \mathrm{~nm}$ wavelength).

(B) Blink frequency responses of $A$. katoptron and distance to dummy triggered by the three distinct LED intensities detected at $504 \mathrm{~nm}$ wavelengths as shown in A. Experiments were repeated 5 times independently and values are given as mean ( \pm SEM). Blink frequencies of $A$. katoptron were decreased with increasing intensities of the LED.

Statistical significance was evaluated with RM ANOVA.

Significance values reported as: ${ }^{* *} p<0.01$. Error bars indicate \pm SEM. 


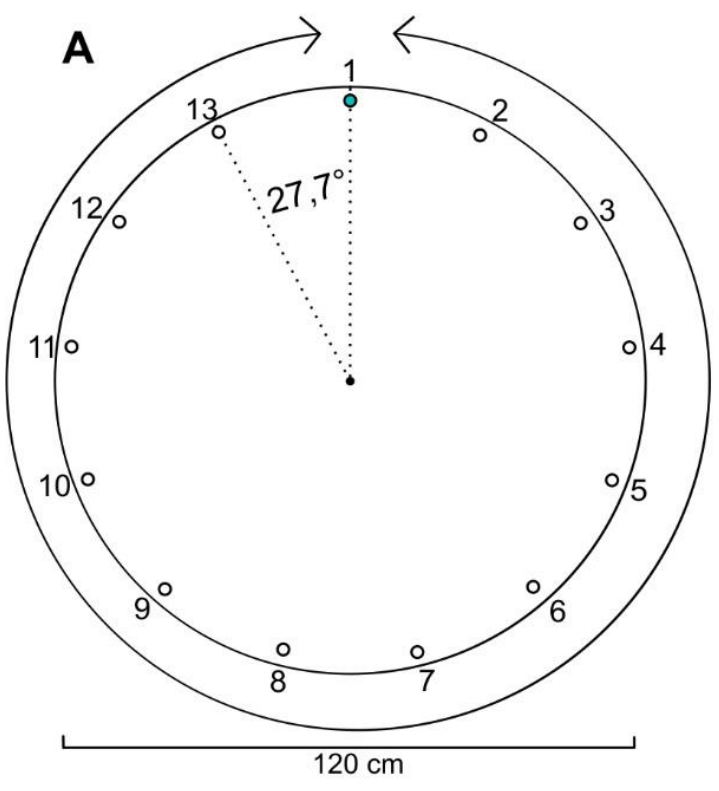

717

\section{Figure S3. A. katoptron follow moving light stimuli.} was tested for 60 seconds. (counter clockwise or clockwise) directions.
B

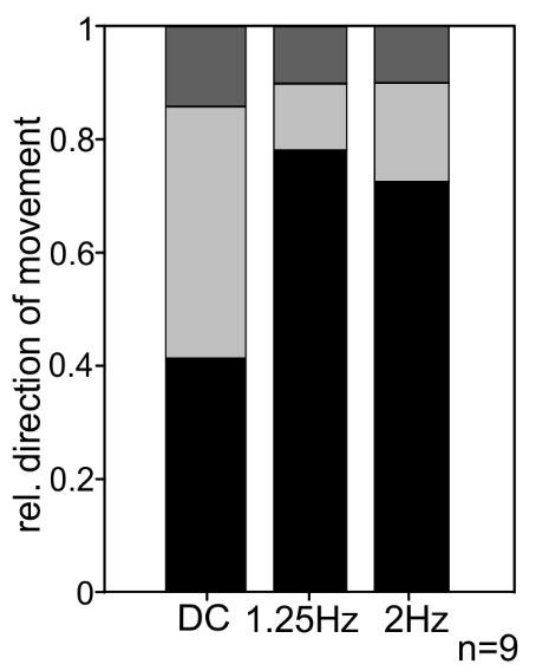

with the light or clockwise (DC) $\square$ against the light or counter clockwise (DC) other

(A) Experimental setup with 13 wall mounted LEDs that were triggered consecutively counter- or clockwise. Intervals between $300 \mathrm{~ms}$ light emittance were 200 or $500 \mathrm{~ms}$ (travelling speed of light: $200 \mathrm{~ms}, 0.58 \mathrm{~m} / \mathrm{s}$; $500 \mathrm{~ms}, 0.36 \mathrm{~m} / \mathrm{s}$ ). Additionally, we performed a control without light stimulation (DC, dark control). Each fish

(B) Relative direction of $A$. katoptron following artificial light sources. Flashlight fish show a high motivation to follow the direction of light $(1.25 \& 2 \mathrm{~Hz})$. In the control experiment (DC) the fish swims equally into both 

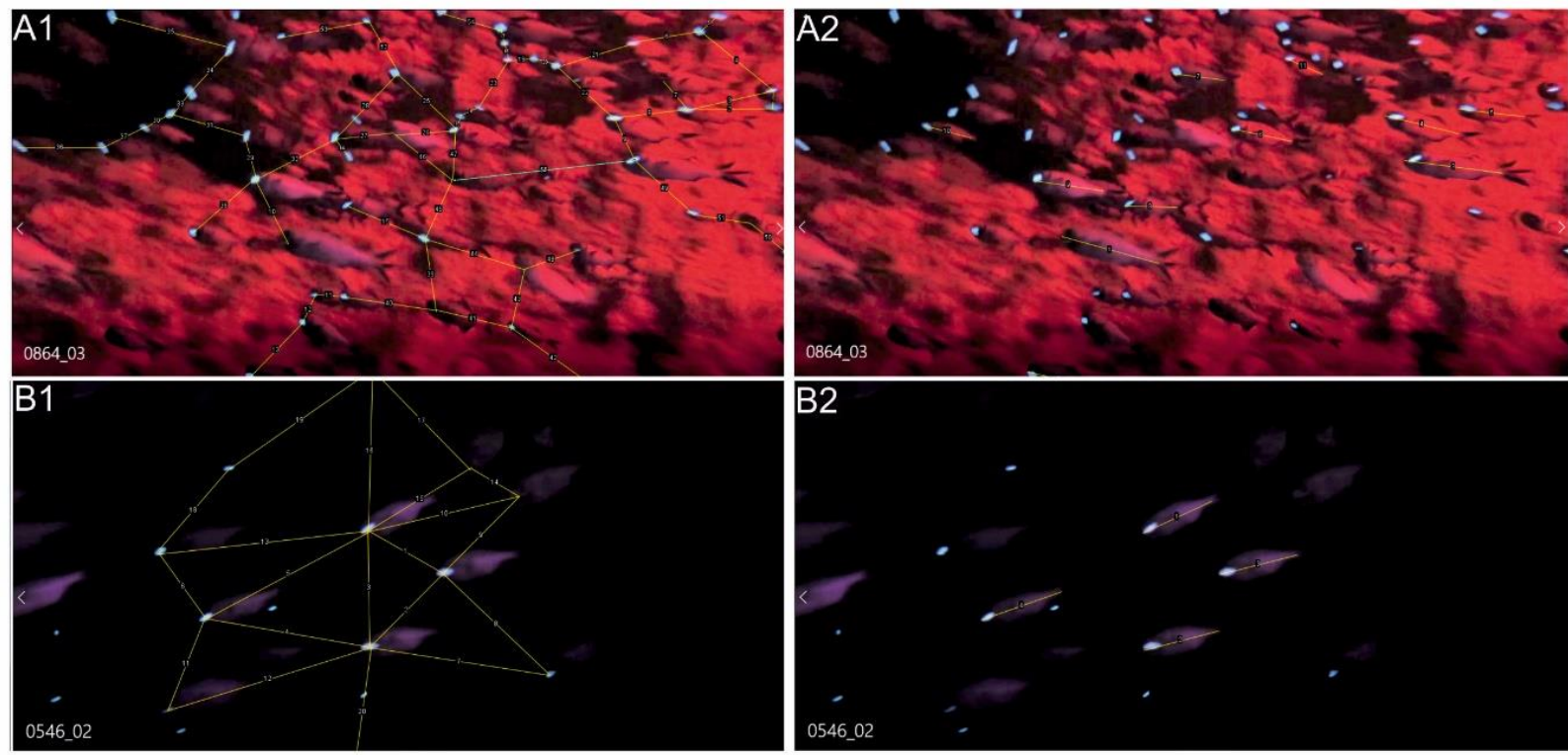

Figure S4. Analyzing the nearest neighbor distance in schools of $A$. katoptron (Ambon, Maluku, Indonesia).

(A) Flashlight fish A. katoptron were illuminated with diving torches (300 lumen red light; Codylight 1500; Germany) to trigger avoidance reactions. For every screenshot, we estimated the fish standard length (SL) as reference (A2) We connected light organs (A1) of individuals that seemed to be neighbors to determine their distances. 46 screenshots were analyzed.

732 (B) Groups of $A$. katoptron while schooling on the reef flat were illuminated with IR-torches and recorded with an infrared camera. Networks connect light organs of potential neighbors (B1) and standard length (SL) was estimated as reference (B2). 37 screenshots were analyzed. 